\title{
XLI. On the planet Vesta
}

\section{S. Groombridge Esq.}

To cite this article: S. Groombridge Esq. (1808) XLI. On the planet Vesta, Philosophical Magazine Series 1, 31:123, 228-229, DOI: 10.1080/14786440808563888

To link to this article: http://dx.doi.org/10.1080/14786440808563888

$$
\text { 曲 Published online: } 18 \text { May } 2009 .
$$

Submit your article to this journal 전

III Article views: 2

Q View related articles $\sqsubset$ 
nishing the force at the expense of the time, or the velocity at the expense of the force; or rather by employing two or more forces instead of une: this gives an infinity of resources for producing the momentum of activity aecessary: but, whatever we do, these means must always be equal, $i . k$. the momentum of activity consumed by the soliciting forces, is equal to the effect or momentum cxercised at the same time by the resisting forces.

[Tobe continaci.]

XLI. On the Planet Vesta. By S. Groombridge, Esq. To Mr. Tilloch.

$\mathrm{T}_{\mathrm{HE} \text { d }}^{\mathrm{sin},}$

iscovery of the planet Vesta, on the 29th of March $180 \%$, having been communicated to this country by $\mathrm{Dr}$. Olbers; on the 20 th of April I fount its place, and observed the same on the meridian. I obtained a series of observations to the 20th of May; after which, from the increase of daylight, it was no lunger visible on the meridian. The observations which were afterwards made were with equatorial instruments; and these cannot be depended on, for sufficient accuracy in calculating the elements. I have, however, used some of these, from the 29th of March to the 2ed of June, to determine the eccentricity; those which were made on the meridian producing nearly the same radius. I thence discovered, that the planet was decreasing iu radius, and therefore conjecture that it was in aphelio about the time it was first seen. When the planet was discovered by Dr. Olbers on the 29th of March, it appears to have been about seven days past the opposition; and it is well known, not having that point of the orbit for a datum, the difficulty of calculation is increased. I was therefore anxious to observe the planet before the ensuing opposition, to obtain sufficient materials for ascertaining all the elements. For this purpose, I assumed a mean radius of the extreme observations; which, if I was right in my conjecture of the aphelium, would prove too great; and therefore the planet should be further advanced in the ecliptic. On the $30 \mathrm{th}$ of July, the evening being clear, and the moon not risen, I observed the difference of right ascension of several stars of 
the sixth magnitude, compared with those laid down in Bode's Catalogue; but in particular five stars, about two degrees advanced in longitude, from the computed place of the planet; not one of which was to be found in that Catalogue; the latitude being nearly the same: I therefore suspected one of these to be Vesta. On the 1st of August the same five stars being bronght into the field of the telescope, it was instantly apparent that one had changed its place, southward and retrograde in right ascension: this was the object of my rescarch. I could not obtain a meridional observation till the 11 th, having been disappointed by the intervention of clouds or vapour. The following were the places as observed on the meridian; from which its course may be discovered.

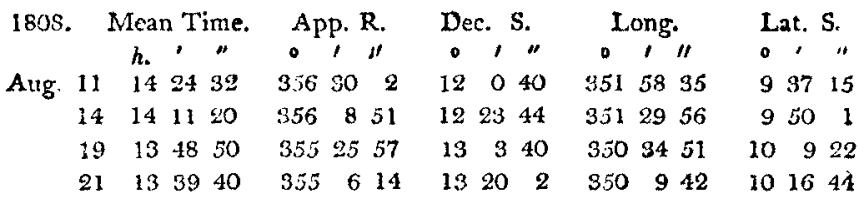

From the observations in last year, I have ascertained part of the elements; which agree very well with those now made.

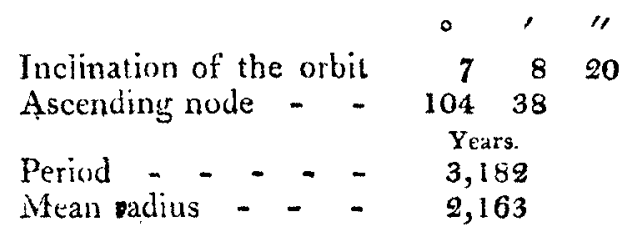

The cccentricity appears to be considerable, from the increased angular motion in its orbit ; but $I$ have not at present sufficient llata to determine the quantity. However, I do conjecture, that Vesta will be nearer to the Earth, about one-fifth the radius of the latter, at the ensuing than at the preceding opposition: which will enable astronomers, viewing the planet with high powers, the better to ascertain its diameter.

The opposition will happen about the gth of September. I am, sir, your obedient servant,

Blackheath,

S. Groombridge. Auguat 28, 1808 . 